DOI 10.37882/2223-2982.2020.04-2.29

\title{
ОСНОВНЫЕ ТРУДНОСТИ ФОРМИРОВАНИЯ ЯЗЫКОВОЙ КОМПЕТЕНЦИИ У СТУДЕНТОВ ТЕХНИЧЕСКИХ СПЕЦИАЛЬНОСТЕЙ
}

\section{MAIN DIFFICULTIES OF FORMING LANGUAGE COMPETENCE FOR STUDENTS OF TECHNICAL SPECIALTIES}

N. Relyan

Summary: The article considers the problem of difficulties in mastering a foreign (English) language by students of technical specialties. The author approaches the solution of the problem through the study of the structure of linguistic competence and the process of its formation in the university. The article identifies and characterizes the main components of language competence; the main difficulties in the formation of language competence are identified, and ways to overcome them in the educational process are also given.

Keywords: foreign (English) language, students of a technical university, the formation of language competence, difficulties.
K онцептуальные трансформации в системе высшего технического отечественного образования в условиях современных реалий обозначены таким ключевыми концептами как: эффективность и качество профессиональной подготовки, обеспечивающие последующую доступность к международному рынку труда и профессий; компетентность будущего профессионала, обусловливающая его высокий уровень востребованности и конкурентоспособности в профессиональной сфере; свободное владение ключевыми квалификациями на уровне международных стандартов, что позволяет будущему специалисту успешно профессионально самореализоваться в различных условиях (в том числе и условиях иноязычного профессионального общения) [2; 5].

В этой связи роль иностранного языка (в нашем случае английского) в осуществлении последующей профессиональной деятельности повышается, исходя из того, что на этапе начальной профессиональной самореализации обучающиеся должны освоить язык именно как средство коммуникации для реализации равноправных профессионально-партнерских отношений. Это обусловливает необходимость эффективного формирования языковой компетенции у студентов, обучающихся по техническим направлениям и специальностям, должный уровень сформированности которой становится сегодня все более необходимым и востребованным [6].

\author{
Рельян Наталья Александровна, \\ Ассистент, Тюменский Индустриальный университет \\ VNRelyan@yandex.ru
}

Аннотация: В статье рассматривается проблема трудностей освоения иностранного (английского) языка студентами технических специальностей. Автор подходит к решению проблемы через исследование структуры языковой компетенции и процесса ее формирования в вузе. В статье выявлены и охарактеризованы основные компоненты языковой компетенции; определены основные трудности в формировании языковой компетенции, а также приведены пути их преодоления в учебном процессе.

Ключевые слова: иностранный (английский) язык, студенты технического вуза, формирование языковой компетенции, трудности.

Таким образом, одной из основных задач обучения иностранному языку студентов технических специальностей является формирование языковой компетенции в том профессиональном контексте, который предписывает направление или специальность.

Необходимо отметить, что языковая компетенция, которая представляет собой многомерный структурный феномен, имеет такие основные компоненты как:

- знания о языке; в данном контексте предполагается, что студенты технического вуза должны во время учебы преумножить знания о таких разделах английского языка как лексика (что, в основном, сопряжено с приобретением и активизацией именно лексики профессиональной, технической, являющейся достаточно трудной для запоминания, усвоением релевантной терминологии и др.), грамматика, фонетика и т.д.; помимо этого, важное значение приобретает еще область невербального знания о языке, усиливающего коммуникативный компонент, а также культурных языковых особенностей и др.;

- речевой опыт обучающихся, который показывает, насколько студент владеет навыками иноязычной коммуникации, каков уровень сформированности языковых умений и навыков и т.д.; в условиях обучения в техническом вузе языковой опыт студентов будет являться уже опытом в специальных 
условиях, которые ориентированы на профессиональную иноязычную коммуникацию; специально созданные, в данном случае, условия освоения языка специальности будут рассматриваться как фактор формирования языковой компетенции уже более высокого уровня, а именно третьей языковой компетенцией (необходимо отметить, что первая языковая компетенция представлена базовыми знаниями, разговорным или бытовым уровнем иноязычного общения, вторая языковая компетенция представлена профессиональной ориентированным специализированным языком или языком специальности), которая в ходе обучения в техническом вузе затрагивается лишь в рамках развития и совершенствования исследовательской компетенции, в контексте работы над которой формируется специальный научный язык или язык новейших технических открытий и т.п.);

- чувство языка, которое студент приобретает на стыке имеющихся речевых знаний и речевого опыта; данный структурный компонент определяет ту степень в процессе формирования языковой компетенции, где уже являются само собой разумеющимися эвристические языковые «открытия», лингвистические инсайты и т.п.; наличие чувство языка прослеживается в уровне владения всеми языковым навыками: аналитико-синтетическая стратегия в чтении, улавливание смысловых узлов и хода мысли коммуникатора в слушании и передачи информации и т.д.) [3; 4].

Эти рассмотренные структурные компоненты и определяют в ходе изучения иностранного (в нашем случае, английского) языка группы основных трудностей в процессе формирования языковой компетенции на этапе начальной профессиональной самореализации.

Трудности процесса формирования языковой компетенции студентов технических специальностей многообразны. Различный характер данных трудностей в условиях освоения иноязычной профессиональной коммуникации, а также языка специальности предопределяет соответствующие пути и методологические подходы к их преодолению с целью совершенствования языковой компетенции.

Так, одной из основных [трудностей] является различный уровень их [студентов] довузовской иноязычной подготовки. Как было рассмотрено выше, языковая компетенции предопределяет равностепенное освоение всех языковых разделов. Методика формирования языковой (а также и иноязычной профессионально-коммуникативной) компетенции основывается на том, что все аспекты конструкции языковой компетенции (семантические, лексико-грамматические, коммуникативные и т.д.) должны быть представлены в единстве, в то время как неоднородность владения и неодновременность освоения студентами (на довузовском этапе) подсистем иностранного языка крайне очевидна.

Поэтапность усвоения и разноуровневость владения иностранным языком становится первой и основной трудностью формирования языковой компетенции обучающихся по техническим направлениям и специальностям.

Так, например, с первых занятий преподаватель уже сталкивается с тем, что ряд студентов едва владеет разговорной речью, большинство может общаться на более сложном социально-бытовом уровне и лишь незначительная часть студентов в рамках своего технического профиля владеет профессиональной лексикой (чаще всего это ІТ-кластер). В данной ситуации преподавателю необходимо выстраивать работу таким образом, чтобы сохранить мотивацию последних и подтянуть до необходимого уровня отстающих.

На данном этапе преподаватель сталкивается с еще одной самой распространенной трудностью - трудностью формирования мотивационной сферы студентов в овладении языковой компетенцией. В этой связи преподаватель, как правило, использует перераспределение аудиторного времени и разработку многоуровневых образовательных модулей для того, чтобы, в первом случае, довести большую часть студентов до уровня общей подготовленности, а во втором, обеспечить сохранение познавательного интереса и активности более подготовленных студентов.

Так, например, если для среднего большинства студентов подойдут такие задания (близком к профессиональной деятельности) как:

How do you say high-beam indicator in Russian? (Например, при изучении темы: «Car's instrument panel») или How do you say указатель давления масла in English? How do you spell that? И т.д.

А для более подготовленной группы студентов целесообразно уже использовать более творческие задания проблемного типа:

\section{Например,}

Place road signs on the map (Расставьте на интерактивной карте следующие предупреждающие знаки).

Symbols for Danger Warning: 1. Railroad crossing with gates. 2. Railway crossing without gates. 3. Intersection with tramway. 4. Crossing. 5. Steep descent. 5. Swing bridge etc.

Многоуровневый задачный подход в разработке интерактивных лингвистических заданий позволит преподавателю сохранить интерес более подготовленных 
студентов и высвободить время для работы с менее подготовленными (в рамках аудиторной деятельности).

Среди трудностей в процессе формирования языковой компетенции (в контексте сниженной мотивации) выделяют и такие как:

- несформированность потребности студентов в практическом использовании иностранного языка в рамках бытового общения и профессиональной специализации;

- нежелание студентов самостоятельно работать над трудностями; данный аспект отражает отсутствие целей в достижении свободного общения на иностранном языке в более широком масштабе: профессиональные темы, смежная профессиональная или научно-исследовательская тематика, социально-профессиональные темы и др.;
- отсутствие понимания студентами необходимости реальной включенности в иноязычное профессиональное поле; данные затруднения возникают в тех случаях, когда обучающиеся просто не знаю, где и как они могут применять английский в процессе работы на производстве.

Данные трудности являются одними из ключевых в процессе формирования языковой компетенции будущих специалистов технического профиля. Их преодоление мотивирует студентов на овладение трудной профессиональной лексикой, ее использование в учебно-исследовательской и научно-исследовательской деятельности, а также на формирование своих языковые портфолио, позволяющих будущим профессионалам быть востребованными на профессиональном рынке международного уровня.

\section{ЛИТЕРАТУРА}

1. Абдыбекова, Н.А. Развитие речевой деятельности студентов при изучении английского языка / Н.А. Абдыбекова, К.Д. Добаев // Интерактивная наука. 2016. - № 3. - С. 46-49.

2. Еныгин, Д.В. Коммуникативный подход к иноязычной профессиональной подготовке будущих специалистов экономического профиля / Д.В. Еныгин, В.0. Мидова, Е.Г. Маслова // Известия Волгоградского государственного педагогического университета. - 2019. - № 4 (137). - С. $72-74$.

3. Митянина, Н.В. Методика обучения английскому языку в технических вузах / Н.В. Митянина // Молодой ученый. - 2019. - №26. - С. 313-315.

4. Михайлов, В.В. Особенности преподавания английского языка в техническом вузе / В.В. Михайлов // Перспективы науки и образования. - 2018. - № 4 (34). - C. 145-149.

5. Фоминых, Н.Ю. Сущность иноязычной профессиональной подготовки будущих специалистов в области информатики и вычислительной техники как педагогического процесса / Н.Ю. Фоминых // Известия Волгоградского государственного педагогического университета. - 2015. - № 5 (100). - С. 69-74.

6. Шерстянникова, Е.А. Формирование языковой компетенции учащихся технического вуза в процессе изучения филологических дисциплин / Е.А. Шерстянникова // Научный диалог. - 2016. - № 7 (55). - С. 314-322. 